\title{
Characteristics of Soil Environment Variation in Oasis-Desert Ecotone in the Process of Oasis Growth
}

\author{
Haifeng $\mathrm{Li}^{1,2,3}$, Fanjiang Zeng ${ }^{1,3,{ }^{*}}$, Dongwei Gui ${ }^{1,3}$, and Jiaqiang Lei ${ }^{1,3}$ \\ ${ }^{1}$ Xinjiang Institute of Ecology and Geography, CAS, Urumqi, \\ 830011, Xinjiang, China \\ ${ }^{2}$ Graduate School of the CAS, 10049, Beijing, China \\ ${ }^{3}$ Cele National Station of Observation \& Research for \\ Desert-Grassland Ecosystem in Xinjiang, Cele, 848300, Xinjiang, China \\ haifengl1984@sina.com, \\ zengfj@ms.xjb.ac.cn
}

\begin{abstract}
Cele Oasis on the southern edge of Tarim Basin was used to investigate the impact of human activity on the soil environment of the oasis- desert ecotone during the oasis expansion process. Since farmland is extending into the oasis-desert ecotone during oasis expansion, reclaimed farmland and control plots within the ecotone were investigated. The variations in soil moisture, soil nutrients and soil particle-size distribution of the two plots to a depth range of $0-100 \mathrm{~cm}$ were discussed. The soil moisture of each layer in the farmland to a depth of 0-100 cm differed significantly from that in the control plot; the former was generally higher than the latter in the same layer, particularly during the farming period (i.e. April-September). Agricultural soil moisture showed a time-variation rule from multimodal to unimodal with increased depth. Soil moisture of the control plot showed a generally monotonic increasing trend with increased depth; however, for the farmland plot, there was a unimodal increasing trend of initial increase and then a decrease with increased depth. Each layer of the farmland plot had a higher soil nutrient composite index than that of the control plot; however, this improving effect of farmland reclamation on soil nutrient conditions in the oasis-desert ecotone decreased with increased depth. The variation of soil particle-size showed a particular regularity under the influence of cultivation, i.e. silt and clay contents in farmland increased obviously and sand contents decreased.
\end{abstract}

Keywords: Soil moisture Soil nutrient· Size distribution· Cele Oasis.

Both oasis expansion and desertification are basic geographical processes in arid regions, and existing research has shown that both oasis expansion and desertification are accelerating in arid regions [1]. Oasis expansion is usually regarded as the opposite to desertification in an arid region, referring to "the process of transformation from desert to oasis in an arid region due to combined action of anthropic and natural factors" [2].

* Corresponding author.

D. Li, Y. Liu, and Y. Chen (Eds.): CCTA 2010, Part I, IFIP AICT 344, pp. 321 334, 2011.

(C) IFIP International Federation for Information Processing 2011 
Despite significant oasis expansion at present, many researchers still emphasize desertification or develop their research toward desertification [3,4] and few discuss variation of the ecological environment during the process of oasis growth. Variation of land coverage always accompanies both desertification and oasis expansion processes and has important impacts on the soil environment [5-9].

Relevant research indicates that both oasis and desert show an increasing trend in Xinjiang while the ecotone between them is decreasing gradually - as has Cele Oasis on the southern edge of the Tarim Basin over the past 50 years: the oasis area increased while oasis-desert ecotone area gradually decreased [1]. The oasis-desert ecotone is an interface where the most frequent exchanges of energy, substances and information occurs between oasis and desert ecosystems, and its soil environment status is a direct reflection and a miniature of external interference such as human activity intensity and natural agent (climate) variation [10]. In arid and extremely arid regions, the oasis growth process presents mostly continuous expansion of production units into the oasis-desert ecotone. These production units are mainly farmland [11]; therefore, the soil environment variation during the expansion process of farmland into the oasis-desert ecotone is a key point, which is helpful to further understand the impact of human factors on the soil environment during the process of oasis expansion as well as the differentiation characteristics of the soil environment.

Cele Oasis on south edge of Tarim Basin has an extremely arid climate and is the example in this paper. The soil environment characteristics of reclaimed farmland and those of a control plot in the oasis-desert ecotone were compared from the perspective of oasis expansion. The specific characteristics following farmland reclamation are discussed: (1) characteristics of soil moisture variation; (2) integrated variation characteristics of soil nutrient indexes; and (3) soil particle-size differentiation characteristics. Following comparison and analysis, the basic rules of soil environment variation in the oasis-desert ecotone during the oasis expansion process are preliminarily discussed.

\section{Profile of Region of Interest}

Cele Oasis (oasis is used in a broad sense here) lies in the middle section of the south edge of Taklimakan Desert and at the north foot of Kunlun Mountain, located at $35^{\circ} 17^{\prime} 55^{\prime \prime}-39^{\circ} 30^{\prime} 00^{\prime \prime} \mathrm{N}$ and $80^{\circ} 03^{\prime} 24^{\prime \prime}-82^{\circ} 10^{\prime} 34^{\prime \prime}$ E. Elevation in Cele County has range 1280-6780 m above sea level. The research site was limited to $1340-1380 \mathrm{~m}$. The mean annual precipitation is $35.1 \mathrm{~mm}$, mean annual evaporation is $2595.3 \mathrm{~mm}$, and mean annual temperature is $11.9^{\circ} \mathrm{C}$; a typical continental arid climate. It is windy all year around, with the prevailing wind direction northwest. Soil type is mainly aeolian sandy soil, with the original soil mostly Quaternary System diluvial-alluvial deposits [12], of light texture, high sand and low clay contents, excellent permeability and poor fertility-water retention [13]. The oasis is surrounded by natural vegetation in the east and west parts, while its southern part connects with mobile dunes and the Gobi desert. The experiment and observations were implemented at the west of the oasis $\left(35^{\circ} 01^{\prime} 20.7^{\prime \prime} \mathrm{N}\right.$ and $\left.80^{\circ} 43^{\prime} 45.9^{\prime \prime} \mathrm{E}\right)$. 


\section{Experimental Plot Selection and Index Measurement}

Farmland was reclaimed in the oasis-desert ecotone in 1994, and one test plot (FP) was constructed, with cotton planted and irrigation by channeling water from the Cele River floods or flood-irrigation with groundwater. The long-term fertilizer input amount was equivalent to that used by local farmers. Thus, it represents the main production unit during the oasis expansion process. One control plot (CP) was selected close to the reclaimed farmland plot as a reference; vegetation on this plot was mainly Alhagi sparsifolia Shap. at coverage of about $38.9 \%$, representing the natural status of the oasis-desert ecotone. The area of each plot was 1 ha. After $15 \mathrm{y}$ of continuous cultivation, observations of soil moisture, nutrients and soil particle-size were analyzed and compared in 2009 with those of the control plot. Since groundwater depth in the test region is $>15 \mathrm{~m}$ [1], the impact of groundwater on agricultural soil moisture was small. The impact of cultivation on the soil environment is mostly in the upper layer, thus soil environmental characteristics only within the depth of $0-100 \mathrm{~cm}$ are discussed.

\subsection{Measurement of Soil Moisture}

Volumetric water content of plot soil was measured with a neutron gauge (CNC503DR model by Beijing Nucleon Apparatus Company) during 1 January to 31 December 2009: every $10 \mathrm{~cm}$ was taken as one layer within 0-60 cm, and every $20 \mathrm{~cm}$ within $60-100 \mathrm{~cm}$, and measurement was conducted once every $5 \mathrm{~d}$. Precipitation was field-measured with a rain-gauge bucket at a meteorological observation site close to the test plot.

\subsection{Sampling and Analysis of Soil Nutrient}

Soil sampling was from the farmland and control plots after cotton harvesting in October 2009. Three points were selected at random in each plot, and samples collected from five soil layers: 0-20, 20-40, 40-60, 60-80 and 80-100 cm. All samples were placed in plastic bags, closed with a seal and sent back to the laboratory for drying in the shade and root-removing treatment. Seven indexes of soil nutrients were analyzed by standard soil test procedures [14], i.e. soil organic matter (SOM), total nitrogen (TN), total phosphorus (TP), total potassium (TK), available nitrogen (AN), available phosphorus (AP) and available potassium (AK). Soil samples from each plot were also used for particle-size analysis using a laser granulometer (Mastersizer 2000, Malvern Instruments, England).

\subsection{Analysis and Evaluation of Soil Nutrient Indexes}

To comprehensively reflect the status of soil nutrients, soil nutrient properties were analyzed and compared using the soil retrogression index (RI) [15]. For specific calculation and analysis, the soil properties of the control plot were used as the baseline. RI value of each soil layer of farmland was obtained using the formula that follows:

$$
\mathrm{RI}=\sum_{i=1}^{n}\left[\left(x_{i}-x_{i}^{\prime}\right) / x_{i}^{\prime}\right] \times 100 \% / n
$$


Where, RI is soil-nutrient composite index, $x_{i}{ }^{\prime}$ is measured soil nutrient index of each layer from the control plot, and $x_{i}$ is the measured value of the same-layer soil nutrient index from the farmland plot (SOM, TN, TP, TK, AN, AP and AK). If RI > 0 for each layer, this indicated that soil nutrient composite indexes from the layer of the farmland plot was higher than that from the same layer of the control; and vice versa if $\mathrm{RI}<0$.

\subsection{Statistical Analysis}

Significance of differences between means was compared by $t$-tests, respectively, between soil nutrient indexes of farmland and control plots. One-way ANOVA was used to compare soil characteristics of the different layers in farmland and control plots, respectively. The least significance range (LSR) method was used for multiple comparisons, and Pearson's correlations method for correlation analysis. ANOVA, LSR and Pearson correlations were all implemented with SPSS 16.0 software.

\section{Results and Analysis}

\subsection{Differentiation Characteristics of Soil Moisture}

There was one year of continuous observations in 2009 of mean soil moisture variation within the soil depths of 0-100 $\mathrm{cm}$ in farmland and control plots (Table 1).

Table 1. Soil moisture discrepancy test at different depth of two plots

\begin{tabular}{ccccc}
\hline \multirow{2}{*}{ Depth $(\mathrm{cm})$} & \multicolumn{2}{c}{ Between plots (t-test) } & & \multicolumn{2}{c}{ Within plot (analysis of variance) } \\
\cline { 2 - 3 } \cline { 5 - 5 } \cline { 5 - 5 } & Sig. (2-tailed) & & FP & CP \\
\hline $0-10$ & $0.026^{* *}$ & & $3.97 \pm 1.77 \mathrm{e}$ & $2.60 \pm 0.73 \mathrm{f}$ \\
$10-20$ & $0.002^{* *}$ & & $6.10 \pm 2.31 \mathrm{de}$ & $3.38 \pm 1.06 \mathrm{ef}$ \\
$20-30$ & $0.000^{* * *}$ & & $7.67 \pm 2.67 \mathrm{de}$ & $3.85 \pm 0.87 \mathrm{de}$ \\
$30-40$ & $0.000^{* *}$ & & $9.06 \pm 3.18 \mathrm{~cd}$ & $4.24 \pm 0.81 \mathrm{~cd}$ \\
$40-50$ & $0.000^{* *}$ & & $10.70 \pm 4.04 \mathrm{bc}$ & $4.63 \pm 0.91 \mathrm{bcd}$ \\
$50-60$ & $0.000^{* *}$ & & $13.16 \pm 5.02 \mathrm{ab}$ & $4.95 \pm 1.14 \mathrm{abc}$ \\
$60-80$ & $0.000^{* *}$ & & $14.83 \pm 4.19 \mathrm{a}$ & $5.17 \pm 1.02 \mathrm{ab}$ \\
$80-100$ & $0.000^{* *}$ & & $12.03 \pm 3.53 \mathrm{abc}$ & $5.50 \pm 1.13 \mathrm{a}$ \\
F Value & & $13.383^{* *}$ & $12.193^{* *}$ \\
\hline
\end{tabular}

Values in each column with the same letter are not significant (LSR) between different soil depth; * $\mathrm{P}<0.05 ; * * \mathrm{P}<0.01$. 
There was a significant difference within $0-10 \mathrm{~cm}$ between farmland and control plots $(P<0.05)$, and a significant difference within all the other layers $(P<0.001)$ (Table 1). The maximum value $(14.83 \%)$ was at $60-80 \mathrm{~cm}$ for the farmland plot and the minimum value (3.97\%) was at the surface layer. This differed to the control plot where the maximum was at $80-100 \mathrm{~cm}$ and the minimum at the surface layer.

Soil moisture of the two plots also showed obvious differentiation characteristics and a particular regularity over time. The soil moisture status at different depths, for each month of the one year is shown in Fig. 1.
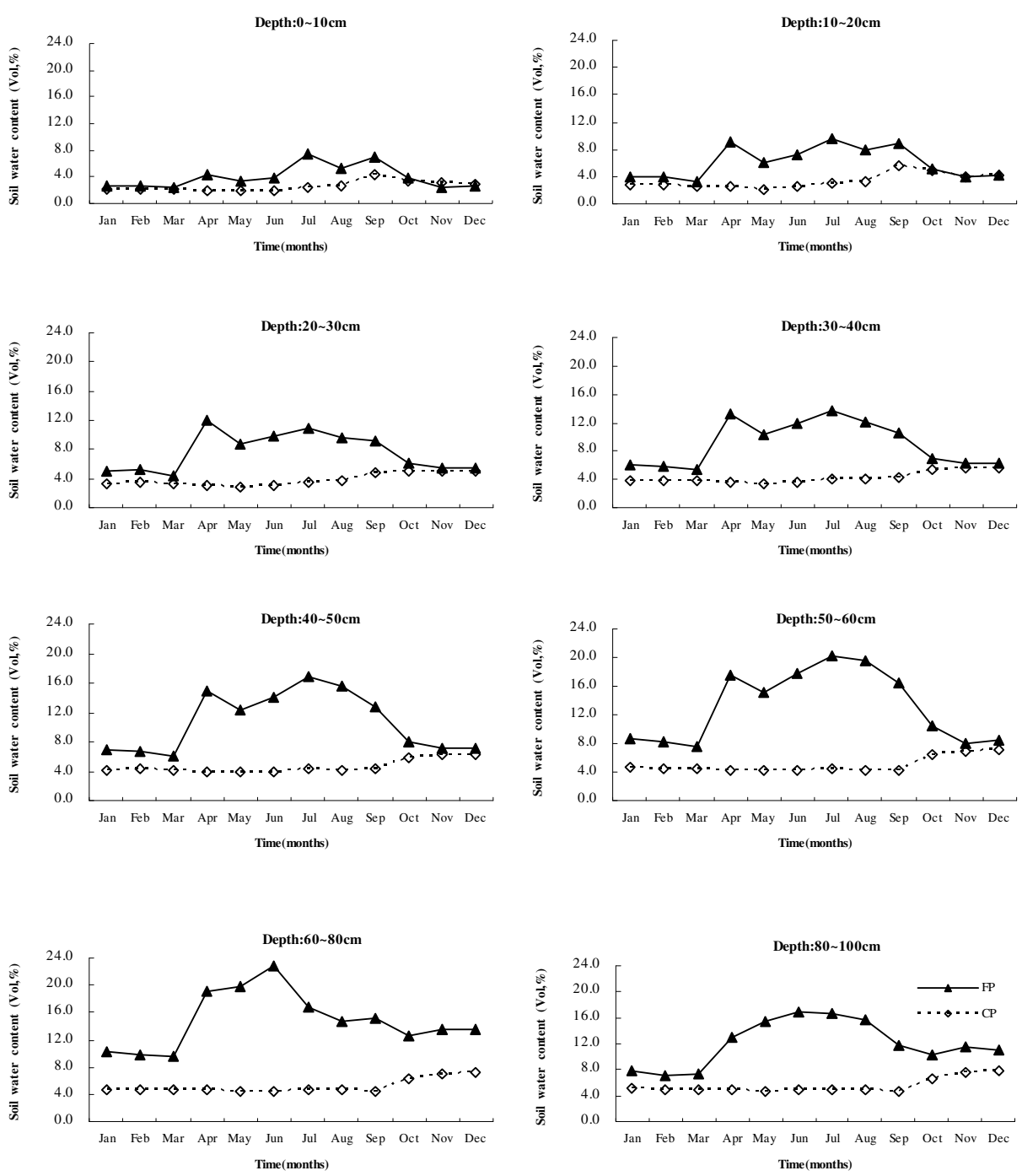

Fig. 1. Seasonal variation of soil moisture at different depths of two plots 
The soil moisture of each layer of the farmland plot was generally always higher than the same layer of the control plot within $0-100 \mathrm{~cm}$ during the different periods (Fig. 1). However, during the fallow periods of January-March and October- December, the difference between farmland and control plots was small, in particular at a depth of $30 \mathrm{~cm}$. During the farming period of March-September, the farmland plot had obviously higher soil moisture than the control plot. The soil moisture content curve for the farmland plots was multimodal at $0-30 \mathrm{~cm}$, bimodal at $40-80 \mathrm{~cm}$, and unimodal at $80-100 \mathrm{~cm}$, i.e. a rule of time variation from multimodal to unimodal presented itself with increased depth.

Variation of soil moisture content at different depths of the two plots over different periods is shown in Fig. 2.

The difference in soil moisture between farmland and control plots at different depths was clear (Fig. 2). Soil moisture of the control plot had a generally monotonic increase with increased depth. There was a unimodal increase in the farmland plot with
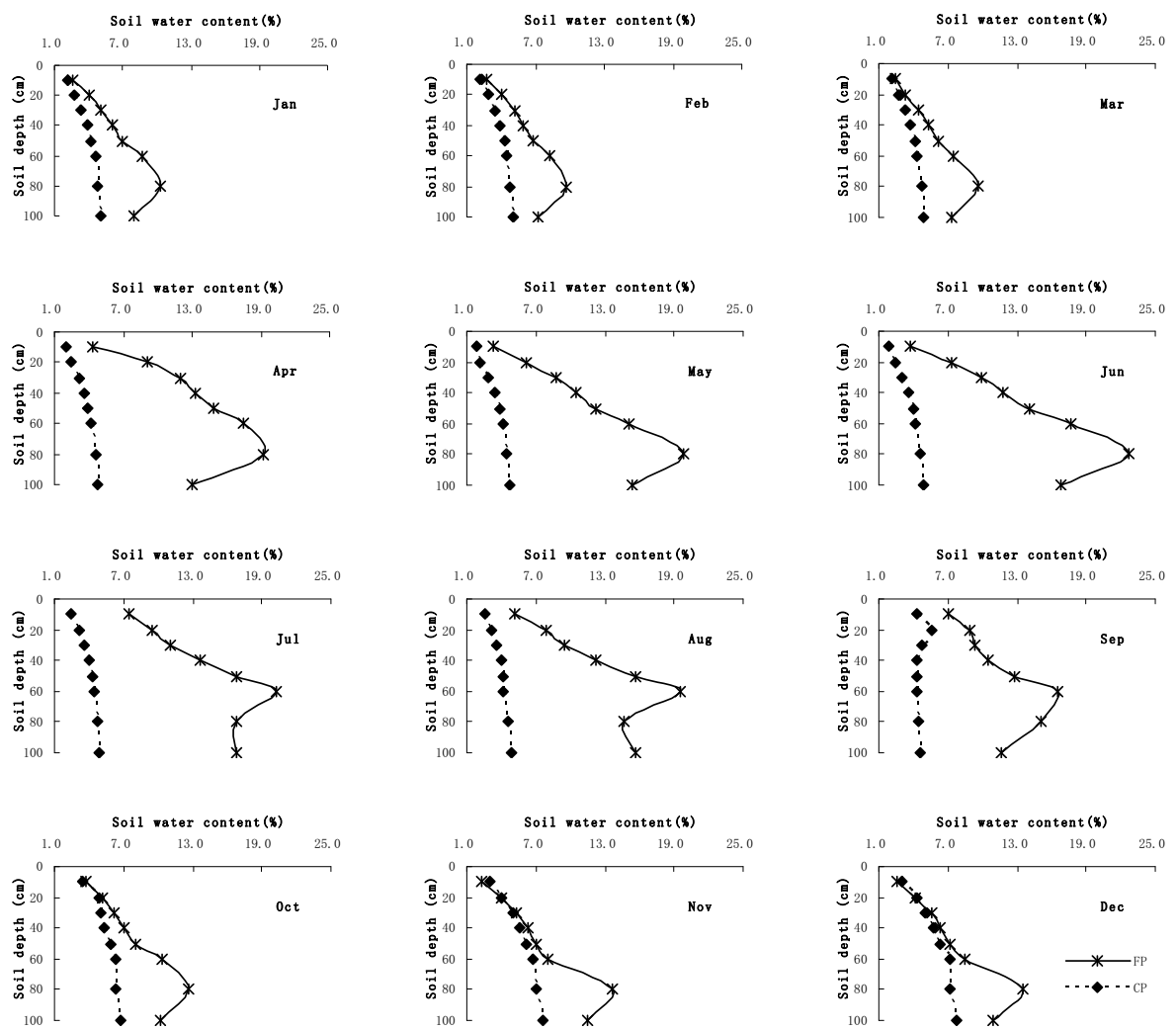

Fig. 2. Vertical variance of soil moisture of two plots during different periods 
increased depth; increasing first and then decreasing, with the peak during July- September at depths of 50-60 cm, and the peak for other months all at depths of 60 $80 \mathrm{~cm}$ (average soil moisture was 14.6\%), similar to the annual mean at this depth (Table 1).

Pearson's correlation analysis indicated that average soil moisture of each layer of the farmland plot within $0-100 \mathrm{~cm}$ had no significant correlation with precipitation; neither did average soil moisture farmland at $0-10 \mathrm{~cm}$ with irrigation volume. However, at $10-20 \mathrm{~cm}$ soil moisture was significantly $(P<0.05)$ and positively correlated with irrigation volume, as was soil moisture of each layer within $20-100 \mathrm{~cm}(P<0.01)$. Soil moisture of the control plot at $0-10$ and $10-20 \mathrm{~cm}$ was significantly $(P<0.01)$ and positively correlated with precipitation. However, there was no significant correlation with precipitation for soil moisture of each layer within $20-100 \mathrm{~cm}$.

\subsection{Comprehensive Variation Characteristics of Soil Nutrient Index}

Based on $t$-tests of nutrient indexes of the two plots, SOM, TN, TP, AN and AP contents of farmland were all significantly $(P<0.05)$ higher than those of the control plot at $0-20 \mathrm{~cm}$. There were no significant differences in the other indexes between farmland and control plots; however, the AK content of farmland was somewhat lower. The difference in SOM, TN and AP contents was significant between farmland and control plots at $20-40 \mathrm{~cm}$, but not in any other index except that $\mathrm{AK}$ of the farmland plot was higher than that of the control. At $40-60 \mathrm{~cm}$, AP content of farmland was

Table 2. Soil nutrient attribute mean and variance analysis of every layer of two plots $($ mean $\pm \mathrm{SD})$

\begin{tabular}{|c|c|c|c|c|c|c|c|c|}
\hline Plot & $\begin{array}{l}\text { Depth } \\
(\mathrm{cm})\end{array}$ & $\operatorname{SOM}(\mathrm{g} / \mathrm{kg})$ & $\mathrm{TN}(\mathrm{g} / \mathrm{kg})$ & $\mathrm{TP}(\mathrm{g} / \mathrm{kg})$ & $\mathrm{TK}(\mathrm{g} / \mathrm{kg})$ & $\mathrm{AN}(\mathrm{mg} / \mathrm{kg})$ & $\mathrm{AP}(\mathrm{mg} / \mathrm{kg})$ & $\mathrm{AK}(\mathrm{mg} / \mathrm{kg})$ \\
\hline \multirow{4}{*}{ FP } & $20-40$ & $3.27 \pm 0.36 \mathrm{ab}$ & $0.16 \pm 0.02 b$ & $0.59 \pm 0.02 \mathrm{a}$ & $23.77 \pm 0.34 \mathrm{a}$ & $2.77 \pm 2.20 \mathrm{c}$ & $5.54 \pm 0.38 b$ & $153.67 \pm 31.21 \mathrm{~b}$ \\
\hline & $40-60$ & $2.68 \pm 0.68 \mathrm{ab}$ & $0.14 \pm 0.06 \mathrm{~b}$ & $0.57 \pm 0.06 \mathrm{a}$ & $24.48 \pm 0.98 \mathrm{a}$ & $6.07 \pm 1.07 \mathrm{~b}$ & $1.61 \pm 0.40 \mathrm{~b}$ & $198.00 \pm 36.43 \mathrm{a}$ \\
\hline & $80-100$ & $2.41 \pm 0.77 \mathrm{~b}$ & $0.12 \pm 0.03 \mathrm{~b}$ & $0.59 \pm 0.04 \mathrm{a}$ & $23.78 \pm 0.67 \mathrm{a}$ & $3.54 \pm 0.88 \mathrm{bc}$ & $3.15 \pm 0.34 \mathrm{~b}$ & $137.33 \pm 9.64 \mathrm{~b}$ \\
\hline & F Value & $5.284^{*}$ & $4.667^{*}$ & $0.448^{\text {ns }}$ & $1.641^{\mathrm{ns}}$ & $15.948^{*}$ & $21.782^{*}$ & $6.024^{*}$ \\
\hline \multirow{3}{*}{$\mathrm{CP}$} & $0-20$ & $2.20 \pm 0.24 \mathrm{a}$ & $0.10 \pm 0.01 \mathrm{a}$ & $0.57 \pm 0.01 \mathrm{a}$ & $23.60 \pm 0.04 \mathrm{a}$ & $1.67 \pm 1.13 \mathrm{~b}$ & $2.33 \pm 0.96 \mathrm{a}$ & $154.67 \pm 25.72 \mathrm{a}$ \\
\hline & $80-100$ & $2.21 \pm 0.31 \mathrm{a}$ & $0.11 \pm 0.01 \mathrm{a}$ & $0.53 \pm 0.01 \mathrm{c}$ & $23.08 \pm 0.96 \mathrm{a}$ & $3.14 \pm 1.66 \mathrm{~b}$ & $1.15 \pm 0.16 \mathrm{~b}$ & $121.33 \pm 7.51 b$ \\
\hline & F Value & $0.486^{\mathrm{ns}}$ & $0.306^{\mathrm{ns}}$ & $5.680^{*}$ & $1.345^{\mathrm{ns}}$ & $11.455^{*}$ & $5.514^{*}$ & $4.179^{*}$ \\
\hline
\end{tabular}

Values in each column with the same letter are not significant (LSR) between different soil depth within each plot; * Significant at $\mathrm{P}<0.05$; ns: Not significant at $\mathrm{P}<0.05$. 
significantly higher than that of the control plot, but not for any other soil nutrient index, although all soil nutrient indexes of farmland were somewhat higher. At 60-80 $\mathrm{cm}$, SOM content of farmland was significantly higher than that of the control plot, but not for any other soil nutrient index. At $80-100 \mathrm{~cm}$, there were no significant differences in all soil nutrient indexes between farmland and control plots.

Multiple comparisons among the nutrient indexes at different depths for the two plots are shown in Table 2.

ANOVA and LSR multiple comparison results showed that soil nutrient discrepancies at different depths of the farmland plot were reflected mainly in SOM, TN, AN, AP and AK indexes; there were no significant differences in TP and TK indexes. SOM, TN, AN and AP contents of farmland at $0-20 \mathrm{~cm}$ were all significantly higher than those of layers deeper than $20 \mathrm{~cm}$. There was no significant difference in SOM content of layers deeper than $20 \mathrm{~cm}$. Within $0-60 \mathrm{~cm}$, SOM content showed a decreasing trend with increased depth. SOM content had a significant impact on TN content [16], and so TN content showed a decreasing trend with increased depth within 0-100 $\mathrm{cm}$ depth. AK content of farmland at 40-60 cm was significantly higher than in all other layers; however, there was no significant difference in AK content of other layers.

There were no significant differences in SOM, TN and TK contents of each soil layer of the control plot within 0-100 cm. Discrepancy in TP content was mainly at 0-40 and 80-100 cm, with no other significant differences in TP content in other layers. The discrepancy in AN index was reflected in AN content at 40-60 cm, which was significantly higher than in any other layer; there was no significant difference in AN content among other soil layers. AP content at $0-20 \mathrm{~cm}$ was significantly higher than that of other layers; however, there was no significant difference among other soil layers. AK content of soil layers within 0-20 cm was significantly higher than that of all other layers deeper than $40 \mathrm{~cm}$, but there was no significant difference in $\mathrm{AK}$ content of soil layers deeper than $20-40 \mathrm{~cm}$.

Composite index RI of soil nutrients in each layer of the farmland plot is shown in Fig. 3. Within $0-100 \mathrm{~cm}, \mathrm{RI}>0$ for all layers of the farmland plot, indicating that the composite index of soil nutrients in each soil layer was higher than that of the control plot. At $0-20 \mathrm{~cm}$, RI of farmland was $186 \%$ higher than in the control plot, indicating that after oasis-desert ecotone soil was reclaimed and became farmland, that the long-term irrigation and fertilization management increased soil nutrient levels. RI was $91 \%$ higher at $20-40 \mathrm{~cm}$, indicating that soil nutrient conditions of this layer had greatly improved compared with the control plot. Within $40-100 \mathrm{~cm}$, RI of each layer was $<40 \%$ and decreased gradually with increased depth, indicating that farmland reclamation only improved soil nutrient conditions of the oasis-desert ecotone within a certain depth, i.e. improvement was gradually weakened with increased depth.

The soil nutrient composite indexes between each layer deeper than $20 \mathrm{~cm}$ and the surface layer $(0-20 \mathrm{~cm})$ of both plots were compared, i.e. the soil properties of each plot at $0-20 \mathrm{~cm}$ were taken as the baseline. RI of layers at 20-40, 40-60, 60-80 and 80-100 $\mathrm{cm}$ of farmland and control plots were calculated with formula (1), and all results were negative (Fig. 4), indicating the soil nutrient composite indexes of both farmland plot and control plot at 0-20 cm were higher than those of deeper layers down to $100 \mathrm{~cm}$. 


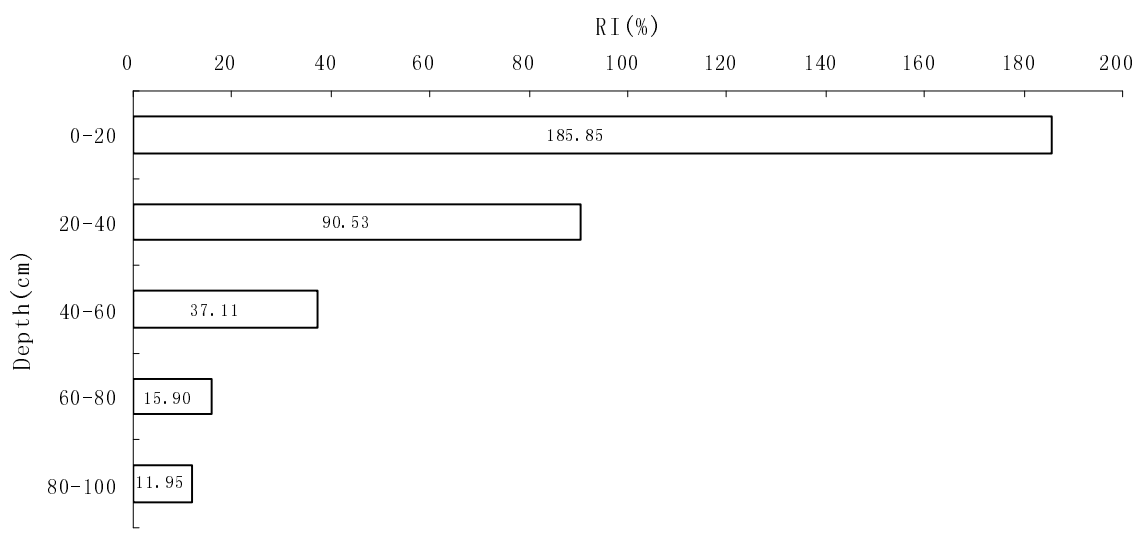

Fig. 3. Composite index of soil nutrient in every layer within 1-m depth of the farmland plot (taking control plot as baseline)

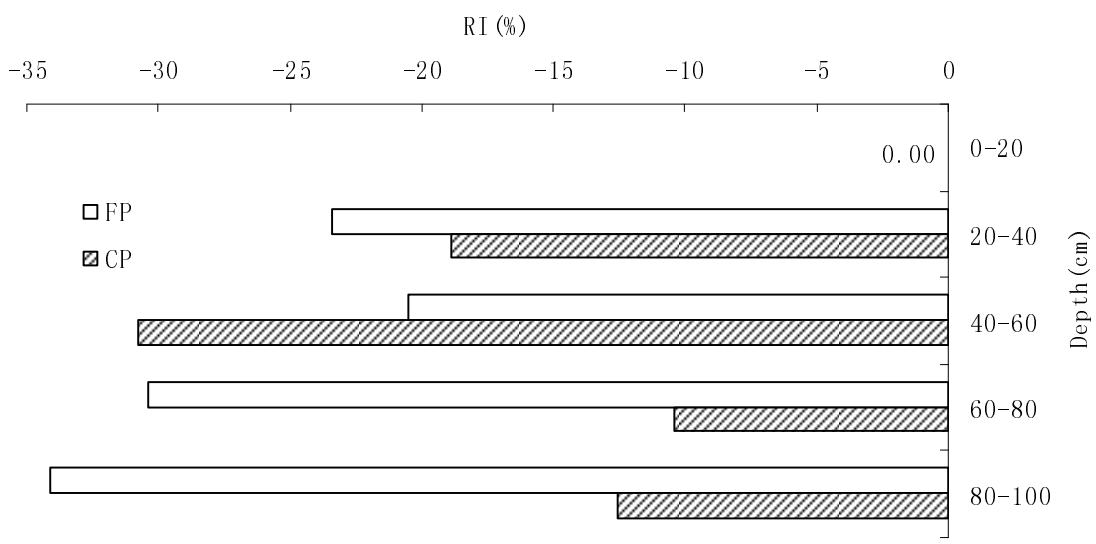

Fig. 4. Composite index of soil nutrient in every layer deeper than $20 \mathrm{~cm}$ of both plots (taking $0-20 \mathrm{~cm}$ as baseline)

\subsection{Differentiation Characteristics of Soil Particle Size}

The soil particle-size distributions of each layer of both plots for $0-100 \mathrm{~cm}$ were within the range $0.35-2000 \mu \mathrm{m}$ (Table 3).

The $t$-tests indicated no significant differences in clay contents between farmland and control plots at $0-20 \mathrm{~cm}$, but the value of the farmland plot was slightly higher than that of the control plot. Silt contents of farmland were significantly higher $(P<0.01)$, and sand contents significantly lower $(P<0.01)$ than the control plot (Table 3$)$. There 
Table 3. Soil size distribution of both plots (mean \pm SD)

\begin{tabular}{ccccc}
\hline \multirow{2}{*}{ Plot } & \multirow{2}{*}{ Depth/cm } & \multicolumn{3}{c}{ Soil size composing /\% } \\
\cline { 2 - 5 } & $0-20$ & Clay $(0.35-2.0 \mu \mathrm{m})$ & Silt $(2.0-50 \mu \mathrm{m})$ & Sand $(50-2000 \mu \mathrm{m})$ \\
\hline \multirow{4}{*}{ FP } & $1.84 \pm 0.41$ & $28.05 \pm 4.28$ & $70.11 \pm 4.65$ \\
& $20-40$ & $1.95 \pm 0.38$ & $27.70 \pm 5.34$ & $70.35 \pm 5.69$ \\
& $40-60$ & $1.67 \pm 1.11$ & $25.55 \pm 10.31$ & $72.79 \pm 11.26$ \\
& $60-80$ & $1.87 \pm 0.38$ & $26.54 \pm 4.72$ & $71.60 \pm 5.02$ \\
& $80-100$ & $1.97 \pm 0.27$ & $26.14 \pm 5.96$ & $71.89 \pm 6.20$ \\
CP & $0-20$ & $1.13 \pm 0.90$ & $20.95 \pm 4.33$ & $77.92 \pm 5.12$ \\
& $20-40$ & $1.69 \pm 0.85$ & $24.95 \pm 5.32$ & $73.36 \pm 6.12$ \\
& $40-60$ & $1.85 \pm 0.40$ & $24.51 \pm 5.23$ & $73.65 \pm 5.62$ \\
& $60-80$ & $1.59 \pm 0.91$ & $23.78 \pm 5.18$ & $74.63 \pm 5.76$ \\
& $80-100$ & $1.86 \pm 0.51$ & $25.23 \pm 6.63$ & $72.91 \pm 7.14$ \\
\hline
\end{tabular}

were no significant differences in clay, silt and sand contents between farmland and control plots at depths of 20-40, 40-60, 60-80 and 80-100 cm, respectively $(P<0.05)$. The impact of cultivation on variation of soil particle-size showed a particular regularity: silt and clay contents in farmland clearly increased and sand contents decreased.

ANOVA indicated no significant differences in clay contents of each layer between farmland and control plots within $0-100 \mathrm{~cm}(P<0.05)$, and similarly for silt contents and sand contents. The soil layer with the highest clay contents in the farmland plot was at $80-100 \mathrm{~cm}$, the highest silt contents at $0-20 \mathrm{~cm}$, and the highest sand contents at 40-60 $\mathrm{cm}$. The soil layer with the highest clay contents in the control plot was at $80-100 \mathrm{~cm}$, the highest silt contents at $80-100 \mathrm{~cm}$, and the highest sand contents at $0-20 \mathrm{~cm}$.

\section{Discussion}

The research on soil moisture of the oasis-desert zone in the middle reaches of the Black River within depths of $0-50 \mathrm{~cm}$ indicated that soil moisture content of the surface layer in a oasis-desert ecotone was lower than that of oasis farmland [17]. A similar result was obtained in our study, and in addition the soil moisture content of each layer within $0-100 \mathrm{~cm}$ in the natural status of the oasis-desert ecotone was found to be lower than that of farmland.

The research on soil moisture characteristics of the oasis-desert ecotone at Minqin indicated a vertical variation of soil moisture with an increasing trend from surface to deeper layer within 0-120 cm [18]. Soil moisture of the desert-oasis ecotone in the middle reaches of the Black River within depths of 0-200 cm increased with increased depth [19]. Our results indicated that within 0-100 cm, the soil moisture of the control plot in the oasis-desert ecotone had a generally monotonic increasing trend with increased depth, consistent with previous findings. Because of poor soil texture in the surface layer of the control plot, weak water-retention capacity and the impact of evaporation and infiltration, the soil moisture content of the surface layer was significantly lower than that of deeper layers. 
The research findings on Kerqin sandy land indicated that precipitation influenced soil moisture content of the surface layer at $0-0.8 \mathrm{~m}$ depth only, due to the consumption of most precipitation by vegetation via transpiration [20]. In this paper, Pearson's correlation analysis indicated a significant positive correlation between soil moisture of aeolian sandy soil of the control plot at $0-20 \mathrm{~cm}$ and precipitation, while no such correlation occurred for layers deeper than $20 \mathrm{~cm}$, indicating that precipitation had an impact on soil moisture content mainly at $0-20 \mathrm{~cm}$, and below that depth the soil moisture may be affected by other factors such as infiltration.

Usually agricultural soil moisture is affected by various factors such as precipitation, irrigation volume, crop growth and climatic conditions. Some findings have indicated that farmland moisture characteristics of arid areas in northern China are affected mainly by evapotranspiration rate [21]. In the event of no groundwater recharge, then precipitation or irrigation would be the main sources of water for farmland, and different precipitation (irrigation) volumes will induce variations in soil moisture [22]. Soil moisture of the farmland plot showed a unimodal increasing trend with increased depth, which increased first and then decreased; of these the peak value was during July-September at a depth of 50-60 cm, and was the result of inconsistent irrigation volumes and irrigation intervals. The soil moisture of each layer of the farmland plot was significantly and positively correlated with irrigation volume within $10-20 \mathrm{~cm}(P$ $<0.05)$ and within $20-100 \mathrm{~cm}(P<0.01)$, indicating that irrigation was the major factor affecting agricultural soil-moisture characteristics within a depth of $1 \mathrm{~m}$. Research by Sun showed that soil moisture during the cotton growth period at Cele was 6.64-13.3\% with irrigation [23]. The average soil moisture range of the farmland plot $(0-80 \mathrm{~cm})$ was 10.83-12.89\% during the cotton growth period (April-October) in this paper, similar to the findings of other researchers - the results can be taken as a guide for local field irrigation.

The acquisition, accumulation and consumption of soil organic matter, nitrogen and phosphorus differ according to diverse land uses and soil tillage [24]; and coverage variation caused by oasis growth also had a significant impact on soil nutrient characteristics [1]. The oasis-desert ecotone has less organic matter accumulation under an original state, while farmland becomes fertile with application of farmyard manure and inorganic fertilizer during growing seasons following crop planting. A composite index of soil nutrient was obtained, based on various soil properties, which effectively reflects soil quality and is helpful for visual comparison and evaluation $[25,26]$. The comparison of RI between the two plots showed that farmland had significantly higher values than that of the control plot, indicating that soil nutrient improvement in the ecotone was positive with certain substance and energy inputs. Soil nutrients reached a maximum in both plots at $0-20 \mathrm{~cm}$, possibly indicating that irrigation and cultivation factors had an impact mainly on the cultivated horizon of farmland; while litter fall of natural vegetation in the ecotone participated in the nutrient cycle, also making soil nutrients in the surface layer of the control plot relatively higher.

Silt and clay contents of the farmland plot were higher than those of the control, but sand content was lower presumably due to the impact of artificial irrigation and cultivation on accumulation of fine soil particles during the oasis expansion process [11]. Sand and silt contents were the major component in upper and lower layers of both 
farmland and control plots, and the proportions were: sand $>$ silt $>$ clay $(<2.00 \%)$, which is the same as the soil size-grade distribution characteristics of the middle Heihe River basin [27], also reflecting poor soil texture in arid regions.

Increasing decomposition of vegetation and inputs of organic matter after reclamation were responsible for the improved soil nutrients. Bouyoucos indicated that an increase in organic matter improved the soil moisture content [28], and organic matter provides the cementation for water-stable soil aggregates [29]. The soil porosity of original sand improved with the increasing trend of organic matter, silt contents and clay contents, thus improving the soil structure.

\section{Summary}

With farmland being the main land use, as a result of population and economic pressures, there are important and positive impacts on the soil environment during the process of expansion into the oasis-desert ecotone. The contrastive analysis of physical and chemical properties (e.g. soil moisture, nutrient and particle sizes) between a 15-y-cultivated farmland plot and a control plot in the ecotone was helpful to obtain a preliminary understanding of variation in soil environmental characteristics in the oasis-desert ecotone.

There was a significant difference in soil moisture of each layer between farmland and control plots within depths of $0-100 \mathrm{~cm}$ due to irrigation. The soil moisture of each layer of the farmland plot during the farming period (i.e. April-September) was generally higher than that of the same layer of the control plot. The agricultural soil moisture showed a time-variation rule from multimodal to unimodal with increased depth. The soil moisture of the control plot showed a generally monotonic increasing trend with increased depth. However, the farmland plot showed a unimodal increasing trend of initial increase and then a decrease with increased depth, with the peak value at $50-60 \mathrm{~cm}$ during July-September and at 60-80 cm during other months.

Under the preconditions of inputs of certain substances and energy, soil nutrient conditions of farmland were obviously improved, and the soil nutrient index was significantly higher than that of the control plot. The improving effect of farmland reclamation on soil nutrient conditions in the oasis-desert ecotone was limited however, and such an improving effect decreased with increased depth. For both farmland and control plots, the soil nutrient composite indexes at $0-20 \mathrm{~cm}$ were clearly higher than those of other layers within $20-100 \mathrm{~cm}$; but the soil nutrient content in both farmland and control plot in oasis-desert ecotone is not high compared with other regions in China. Cultivation and management had a positive impact on soil particle-size distribution in the oasis-desert ecotone: silt contents and clay contents in the farmland soil obviously increased while sand contents decreased.

Acknowledgements. The project was supported by the National Basic Research Program of China (973 program 2009CB421302), Technology Key Project of Xinjiang (Grant No.200733144-2), The National Science and Technology Supporting Program of China (2009BAC54B01) and National Natural Science Foundation of China 
(NO.41001171). The authors also thank the anonymous reviewers for their valuable comments.

\section{References}

1. Gui, D.W., Lei, J.Q., Mu, G.J., Zeng, F.J.: Effects of different management intensities on Soil quality of farmland during oasis development in southern Tarim Basin, Xinjiang, China. Int. J. Sustain. Dev. World. Ecol. 16, 295-301 (2009)

2. Wang, T.: Review and Prospect of Research on Oasification and Desertification in Arid Regions. J. Desert Res. 29, 1-9 (2009) (in Chinese)

3. Bridges, E.M., Oldeman, L.R.: Global Assessment of Human-Induced Soil Degradation. Arid Soil Res. Rehabil. 13, 319-325 (1999)

4. Zhao, W.Z., Xiao, H.L., Liu, Z.M., Li, J.: Soil degradation and restoration as affected by land use change in the semiarid Bashang area, northern China. Catena 59, 173-186 (2005)

5. Lepsch, I.F., Menk, J.R.F., Oliveira, J.B.: Carbon storage and other properties of soils under agriculture and natural vegetation in Sao Paulo State. Brazil Soil Use Manage 10, 34-42 (1994)

6. Hontoria, C., Saa, A., Rodríguez-Murillo, J.C.: Relationships between soil organic carbon and site characteristics in Peninsular Spain. Soil Sci. Soc. Amer. J. 63, 614-621 (1999)

7. Sainju, U.M., Singh, B.P., Whitehesd, W.F.: Long-term effects of tillage, cover crops, and nitrogen fertilization on organic carbon and nitrogen concentrations in sandy loam soils in Georgia, USA. Soil Res. 63, 167-179 (2002)

8. Su, Y.Z., Zhao, H.L., Zhang, T.H., Zhao, X.Y.: Soil properties following cultivation and non-grazing of a Semi-arid sandy grassland northern China. Soil Res. 75, 27-36 (2004)

9. Heenan, D.P., Chan, K.Y., Knight, P.G.: Long-term impact of rotation, tillage and stubble management on the loss of soil organic carbon and nitrogen from a Chromic Luvisol. Soil Till. Res. 76, 59-68 (2004)

10. Tang, L.S., Zhang, J.B., Cheng, X.J., Du, E.H.: Land Degradation and Ecological Regeneration in the Ectones between the Oases and Deserts in the Arid Areas. Arid Zone Res. 19, 43-48 (2002) (in Chinese)

11. Gui, D.W., Lei, J.Q., Zeng, F.J., Mu, G.J., Zhu, J.T.: Characterizing variations in soil particle size distribution in oasis farmlands-A case study of the Cele Oasis. Math. Comput. Modelling 51, 1306-1311 (2010)

12. Zeng, F.J., Bleby, T.M., Landman, P.A., Adams, M.A., Arndt, S.K.: Water and nutrient dynamics in surface roots and soils are not modified by short-term flooding of phreatophytic plants in a hyperarid desert. Plant Soil 279, 129-139 (2006)

13. Zeng, F.J., Lei, J.Q., Zhang, X.M.: Cele Oasis: Environmental characteristics of Desert Transitional Area and Dominant plants adaptation, p. 6. Science Press, Beijing (2010) (in Chinese)

14. Editorial Committee: Soil Physical and Chemical Analysis and Description of Soil Profile, pp. 31-43. Standards Press of China, Beijing (1996) (in Chinese)

15. Davidson, E.A., Ackerman, I.L.: Changes of soil carbon inventories following cultivation of previously untilled soils. Biogeochemistry 20, 161-193 (1993)

16. Brubaker, S.C., Jones, A.J., Lewis, D.T., Frank, K.: Soil properties associated with landscape positions. Soil Sci. Soc. Amer. J. 57, 235-239 (1993)

17. Zhang, B., Meng, B., Hao, J.X., Ding, W.H.: Heterogeneity of Soil Moisture and Salt Contents and Its Eco-environmental Effects in Oasis-desert Belt in Arid Zone. J. Desert Res. 26, 81-84 (2006) (in Chinese) 
18. Wang, B., Cui, X.H.: Research on laws of water balance at transitional zone between oasis and desert in Minqin. Acta Ecologica Sin. 24, 235-240 (2004) (in Chinese)

19. Liu, B., Zhao, W.Z., Chang, X.X., Li, S.B., Zhang, Z.H., Du, M.W.: Water requirements and stability of oasis ecosystem in arid region, China. Environ. Earth. Sci. 59, 1235-1244 (2010)

20. Zhao, H.L., Zhao, X.Y., Zhang, T.H.: The Process of Desertification and its Mechanisms of restoration in Horqin Sandy Land, pp. 202-205. Ocean Press, Beijing (2003) (in Chinese)

21. Kang, S.Z., Zhang, L., Liang, Y.L., Hu, X.T., Cai, H.J., Gu, B.J.: Effects of limited irrigation on yield and water use efficiency of winter wheat in the Loess Plateau of China. Agr. Water Manage. 55, 203-216 (2002)

22. Deng, T.H., Fu, X.J., Shen, S.H., Zhu, Z.X.: Transforming model of soil moisture between layers of 0-50 cm and 0-100 cm. Agr. Res. in Arid Areas 23, 64-68, 120 (2005) (in Chinese)

23. Sun, Y.Q., Zhao, Y.J., Zhang, X.M.: Preliminary Study on Water-saving Irrigation Model of Three Crops in Cele. Arid Zone Res. 16, 56-60 (1999) (in Chinese)

24. Risser, P.: Range condition analysis: past, present and future. In: Lauenroth, W., Laycock, W. (eds.) Secondary Succession and the Evaluation of Range land Condition, Boulder Colo, pp. 143-156. Westview Press (1989)

25. Fu, B.J., Meng, Q.H.: Effects of land use on soil erosion and nitrogen loss in the hill area of the loess plateau. Land Degrad. Dev. 15, 87-96 (2004)

26. Erkossa, T., Itanna, F., Stahr, K.: Indexing soil quality: a new paradigm in soil science research. Aust. J. Soil Res. 45, 129-137 (2007)

27. Zhao, W.Z., Liu, B., Zhang, Z.H.: Water requirements of maize in the middle Heihe River basin, China. Agr. Water Manage. 97, 215-223 (2010)

28. Bouyoucos, G.J.: Effect of organic matter on water-holding capacity and the wilting point of mineral soils. Soil Sci. 47, 377-383 (1939)

29. Ma, Q., Yu, W.T., Zhao, S.H., Zhang, L.: Relationship Between Water-Stable Aggregates and Nutrients in Black Soils After Reclamation. Pedosphere 17, 538-544 (2007) 